УдК 316.774:316.344.233

\title{
СРЕДСТВА МАССОВОЙ ИНФОРМАЦИИ И НОВЫЕ МЕДИА КАК ФАКТОР ВЛИЯНИЯ НА ПРЕОДОЛЕНИЕ ФЕНОМЕНА БЕДНОСТИ В РОССИЙСКОЙ ФЕДЕРАЦИИ
}

\author{
Верещагин Илья Федорович 1 , \\ i.vereschagin@narfu.ru \\ Вахрушев Артем Владимирович1, 2, \\ a.vahrushev@narfu.ru \\ ${ }^{1}$ Северный (Арктический) федеральный университет имени М.В. Ломоносова, \\ Россия, 163002, г. Архангельск, наб. Северной Двины, 17 \\ ${ }^{2}$ Администрация губернатора Архангельской области \\ и правительства Архангельской области, \\ Россия, 163000, г. Архангельск, пр. Троицкий, 49
}

Верещагин Илья Федорович, кандидат исторических наук, доцент кафедры философии и социологии Северного (Арктического) федерального университета имени М.В. Ломоносова.

Вахрушев Артем Владимирович, соискатель кафедры философии и социологии Северного (Арктического) федерального университета имени М.В. Ломоносова; советник губернатора Архангельской области.

Актуальность. По данным Росстата на 1 января 2021 г., 12,1 \% населения Российской Федерации находится за чертой абсолютной бедности (т. е. имеют среднедушевой доход ниже утвержденного в стране прожиточного минимума). Использование относительного или субъективного подхода в оценке уровня бедности приведет нас еще к более удручающим данным. Целью исследования является изучение влияния средств массовой информации и новых медиа на формирование моделей выхода из ловушек бедности домохозяйств, попавших или находящихся в трудной ситуации. Методы: анализ материалов государственной статистики и результатов проведения анкетных опросов населения на региональном уровне (в Архангельской области), семантический и контент-анализ информационных материалов, анализ синонимов и ассоциаций, а также материалов, размещаемых в СМИ и новых медиа, с помощью информационно-аналитической системы «Медиалогия». Выводы заключаются в том, что средства массовой информации и новые медиа, несомненно, являются важным фактором влияния на преодоление феномена бедности в Российской Федерации. Результаты показывают, что для оказания целевой своевременной помощи малообеспеченным слоям населения параллельно с созданием прикладных механизмов социальной поддержки и экономического развития необходимо выстраивать эффективные каналы массовой коммуникации, основная цель которых помочь человеку, попавшему в сложную жизненную ситуацию, оперативно найти источник необходимой информации и воспользоваться ей для изменения своей ситуации. При этом информирование населения должно быть первостепенной задачей. Авторами были сформулированы подробные рекомендации органам государственной и муниципальной власти Архангельской области по количественной и качественной корректировке информационного пространства, которые могут быть использованы и в других регионах Российской Федерации.

Ключевые слова: Бедность, малоимущие, средства массовой информации, новые медиа, семантическое ядро, поисковый запрос, каналы информирования и коммуникации, Архангельская область, присутствие в сети, сценарии и модели поведения, трудная жизненная ситуация, меры социальной поддержки, ловушки бедности, мотивация, стимулы. 


\section{Введение}

По предварительным данным Росстата на конец 2020 г., 12,1 \% населения Российской Федерации находятся за чертой абсолютной бедности (т. е. имеют среднедушевой доход ниже утвержденного в стране прожиточного минимума) [1]. Использование относительного или субъективного подхода приведет нас еще к более удручающим результатам. Сколько человек знает об этих цифрах? Какова доля тех, кто сам находится или рискует оказаться в сложной ситуации, хочет ее преодолеть, но не знает, куда ему обратиться? Где найти эту информацию? Как донести до людей, которые зачастую не используют традиционные СМИ или не имеют необходимого уровня образования, информацию о мерах поддержки и помощи в доступной для них форме? Именно на эти вопросы мы постарались ответить в нашей статье.

Средства массовой информации и новые медиа - одна из важнейших институциональных форм, входящих в состав базового института «Культура/Идеология» любого общества. От информирования зависит наше отношение к малоимущим гражданам (возможная полярность от презрения/страха до искренней жалости и желания оказать помощь и поддержку), а самое главное - повышение вероятности того, что человек, попавший в трудную жизненную ситуацию, сумеет ее оперативно преодолеть, и, наконец, от этого зависит, смогут ли люди, которые испытывают нужду на постоянной основе, переломить ситуацию для себя и своих близких и выбраться из ловушки бедности.

Авторами статьи выдвигается гипотеза о том, что при определении дискурса, связанного с феноменом бедности, и соответствующих информационных каналов идет некорректное формирование как содержания (в том числе, использование некорректного семантического ядра), так и форм и каналов информирования. Следовательно, весь массив данных, формируемый в средствах массовой информации и новых медиа по тематике бедности, никак не влияет на мотивацию малоимущих к изменению ситуации, потому что они либо не видят необходимую информацию, либо не воспринимают ее правильным образом, либо не могут ее обнаружить в случае попадания в сложную жизненную ситуацию.

Объект исследования - это средства массовой информации и новые медиа Российской Федерации. Предмет исследования - содержание информации по тематике бедности и каналы ее поступления к целевой аудитории. Целью данного исследования является изучение влияния средств массовой информации и новых медиа на формирование моделей выхода из ловушек бедности домохозяйств, попавших или находящихся в положении бедности.

Для достижения цели исследования авторы сформулировали ряд задач:

1. Проанализировать источники и теоретически обосновать коммуникацию в качестве мезоуровня структурирования модели взаимодействия малообеспеченных граждан и средств массовой информации, новых медиа на современном этапе развития российского общества.

2. Проанализировать действующую систему массовой коммуникации на предмет популярности и уровня доверия со стороны населения, в том числе федеральные, региональные, местные средства массовой информации и новые медиа.

3. Провести анализ взаимосвязи уровня доверия населения к данной институциональной форме и уровня дохода домохозяйства (на примере Архангельской области), выявить формулировки поисковых запросов, применяемых целевой аудиторией для поиска необходимой информации.

4. Провести семантический анализ слова «бедность», соответствующих ему лексем, выражений, сценариев и форм контента, применяемого российскими средствами массовой информации и новыми медиа на современном этапе. 
5. Сформулировать рекомендации органам государственной и муниципальной власти по корректировке информационного пространства.

Основными методами исследования служат анализ материалов государственной статистики; результатов проведения анкетных опросов населения на региональном уровне (в Архангельской области); поисковых запросов в сети Интернет; семантический и контент-анализ информационных материалов, анализ синонимов и ассоциаций, а также анализ материалов, размещаемых в СМИ и новых медиа, с помощью информационно-аналитической системы «Медиалогия».

\section{Теоретические модели влияния коммуникации на социальные феномены}

Еще в XIX в. Макс Вебер отмечал способность воздействия печатных средств массовой информации на изменение модели поведения индивида. Джордж Герберт Мид через концепцию символического интеракционизма формулировал создание реальности через практическую деятельность. Пол Лазарсфельд дополнил возможности воздействия средств массовой информации, представив двухуровневую модель, раскрывающую роли «лидеров мнений» [2].

В настоящее время практически все население планеты вовлечено в процесс массовой коммуникации, часто это взаимодействие реализуется виртуальным способом. Возможностям влияния СМИ и новых медиа на формирование моделей поведения посвящены в том числе и работы С.Г. Ушкина [3], Ю.А. Поповой [4], С.В. Капраловой [5] и других исследователей. Согласно результатам исследований, данная институциональная форма является инструментом воздействия на внутреннюю мотивацию и заинтересованность индивида, устойчивым каналом для его формирования и укоренения в сознании [6]. Таким образом, средства массовой информации и новые медиа, реализующие свои возможности как в цифровом, так и в традиционном формате, оказывают влияние на формирование окружающего мира человека, который базируется на передаваемых и воспринимаемых образах, символах, стереотипах и реализуется в реальных социальных практиках.

По мнению авторов, задача любого средства массовой информации или представителя нового медиа при борьбе с бедностью - создавать правильные и устойчивые модели поведения индивида (сценарии, алгоритмы действий) при попадании в трудную жизненную ситуацию, а впоследствии и в ловушку бедности. Для того чтобы создавать эффективный контент и информационные каналы, СМИ/новые медиа должны прежде всего понять, на кого они воздействуют (т. е. иметь четкие профили и причины бедности) и каков уровень заинтересованности у индивида преодолеть ситуацию (т. е. четко понимать его мотивы). Мотивы необходимы для формирования внешних стимулов (в данном случае содержания и формы контента и каналов его продвижения), трансляторами которых и является система массовой коммуникации. Точка соприкосновения внутреннего мотива и внешнего стимула как раз и является тем мезоуровнем социальной системы, основой которого служит коммуникация.

Как известно, без адекватной теоретической модели невозможно создать эффективный практический инструментарий, в том числе и для борьбы с бедностью. Понятие «коммуникация» в качестве интегративного элемента жизнедеятельности подробно рассмотрено в коммуникативной концепции структурирования социальности, которая трансформирует ее в определенный «метадискурс». Под дискурсом авторы понимают событие, в момент которого субъект и объект интеракции встречаются, это особый тип реальности, основное свойство которого - это непрерывное и последовательное преобразование во времени. Это понятие применяли М. Фуко, Ю. Хабермас, Э. Лакло, Э. Гоулднер, Т. Дюрберг, Ж. Деррида [7]. 
Коммуникативная концепция образовалась в период постструктурализма и развивалась такими учеными, как Р. Барт, М. Фуко, Ж. Лакан. Мишель Фуко активно использовал понятие «дискурс» как в речевом плане, там и в мыслительном. Точка пересечения представления о реальности и самой реальности, жизнедеятельности индивида и жизни общества и есть дискурс, т. е. трансляция теоретической модели структурирования социальности путем коммуникации и внедрение ее в сознание человека. Дискурс это не что иное, как средство социальной коммуникации, стимул, оказывающий воздействие на мотивы личности. По мнению М. Фуко, индивид находится на пересечении различных дискурсов, не являясь независимым и подвергающимся воздействию языковых практик. Язык выступает первичным элементом структурирования, далее начинают работать социальные, культурные механизмы следующих уровней, в том числе коммуникативные социальные практики и система массовой коммуникации [8].

Одним из наиболее интересных вариантов применения коммуникации как интегративного элемента выступает «теория коммуникативного действия» Юргена Хабермаса. Вместо вопроса, как возможен социальный порядок, Ю. Хабермас спрашивает о том, каким образом участники коммуникации координируют свои действия, не провоцируя конфликта и не разрушая саму интеракцию. Механизмом данного процесса является взаимопонимание. Обычно действие - это постижение ситуации, а коммуникативное действие должно реализовывать постижение совместно на условиях консенсуса. При реализации каждым из участников своих планов возникает потребность договариваться с остальными участниками интеракции. И именно коммуникация между индивидами служит мезоуровнем, объединяющим общественные структуры и человека. Это основа, вокруг которой формуется социальность, состоящая как из объективного, так и из субъективного миров [9].

Коммуникация - это базис для создания социальных систем. Ее внутренняя структура формирует связи между сообщением, данными и восприятием. Понимание является важной частью процесса интеракции, но достигается не всегда, и это приводит к новому общению, перманентно воспроизводя коммуникационные процессы. Цель этого процесса - это воспроизводство смыслов, которое одновременно является и результатом интеракции. Таким образом, интеракция между участниками общения и есть тот необходимый мезоэлемент, интегрирующий макро- и микроуровни социальности, общество и индивида. Именно коммуникация является стержнем, на который нанизываются элементы объективного и субъективного [9].

Никлас Луман полагал, что коммуникация является базисной единицей построения социальности, основой для дальнейших социальных операций [10]. Сам процесс интеракции основан на понимании, в случае недостижения которого необходима новая коммуникация. Следовательно, коммуникативный процесс предполагает постоянное непрерывное общение автора и адресата до полного понимания вторым необходимого дискурса и корректировки своего индивидуального поведения. Цель коммуникации это перманентное воспроизводство и конструирование социальности и ее изменений [10].

Дискурс как основу социальности также отмечал Т. Липовац, говоря о том, что существование и сочетание различных типов дискурсов корректируют отношение индивида к общей ситуации и к самому себе: «Структурное начало стало бы здесь тождественным с признанием существования различных типов дискурса в обществе, которые необходимым образом артикулируют отношение субъекта к делу, к самому себе и к значимым социальным практикам» [11, p. 165]. Урс Стахели предпринимал попытки сопоставить два типа структур: социальную и семантическую. Семантика, по его мне- 
нию, создает элементы, способные упорядочить саму социальную структуру, являясь основой социальности [12].

Активный рост и развитие информационно-коммуникационных технологий характеризуются возрастанием масштабов и разнообразия выпускаемого контента, что последовательно оказывает серьезное воздействие на жизнедеятельность индивида, его нормы и ценности, стереотипы и способы принятия решений, а также восприятия и усвоения информации [13]. С совершенствованием глобальной системы массовой коммуникации (в том числе, доступности средств массовой информации и новых медиа) коммуникативная концепция структурирования социальности актуальна как никогда. При формировании современных теоретических моделей и реализации практических механизмов влияния институциональных форм (например, СМИ и новые медиа) на любой социальный феномен (например, на феномен бедности) целесообразно применение интегративного подхода. Но при его безусловном применении важно учесть несколько принципиальных моментов. Это прежде всего соотношение методов, взятых из микрои макрометодологии и определение мезоуровней (точек интеграции) при анализе конкретного феномена. В данной статье в качестве мезоуровня рассматривается коммуникация, посредством которой происходит процесс взаимного влияния и преобразования средств массовой информации и индивидов, попавших в трудную жизненную ситуацию или ловушку бедности.

\section{Анализ действующей системы информирования в Российской Федерации}

По мнению экспертов, средства массовой информации и новые медиа могут серьезно воздействовать на формирование ценностей и моделей поведения индивида в обществе. Основное преимущество этих коммуникационных каналов - в их доступности и масштабе, скорости донесения информации. Именно через СМИ и новые медиа человек воспринимает общественные ценности, традиции, порядок поведения. Продвигаемые ролевые модели, ценностные ориентации активно используются потребителями информации [14].

Для оказания целевой своевременной помощи малообеспеченным слоям населения параллельно с созданием прикладных механизмов социальной поддержки и экономического развития необходимо выстаивать эффективные каналы массовой коммуникации, основная цель которых помочь человеку, попавшему в сложную жизненную ситуацию, оперативно найти источник необходимой информации и воспользоваться ей для изменения своей ситуации.

Согласно основным результатам аналитического отчета «Российский медиаландшафт - 2020», опубликованного «Левада-центр» 20 мая 2020 г., 74 \% респондентов подтвердили, что в качестве основного источника информации используют телевидение [15]. С одновременным замедлением темпов падения его использования растет пользование интернет-источников и социальных сетей. При этом социальные сети становятся все более популярными в возрастной группе от 40 до 54 лет [15].

Иерархия наиболее популярных СМИ в Российской Федерации в феврале 2021 г. (по данным информационно-аналитической системы «Медиалогия») представлена на рис. 1) [16].

Всероссийский центр изучения общественного мнения (далее - ВЦИОМ) в феврале 2021 г. провел исследование уровня одобрения деятельности общественных институтов, в том числе средств массовой информации [17]. Деятельность СМИ одобрили свыше $42 \%$ опрошенных, порядка $40 \%$ не одобрили. При этом в динамике индекс одобрения значительно снизился с 31 января 2020 г. (рис. 2). 


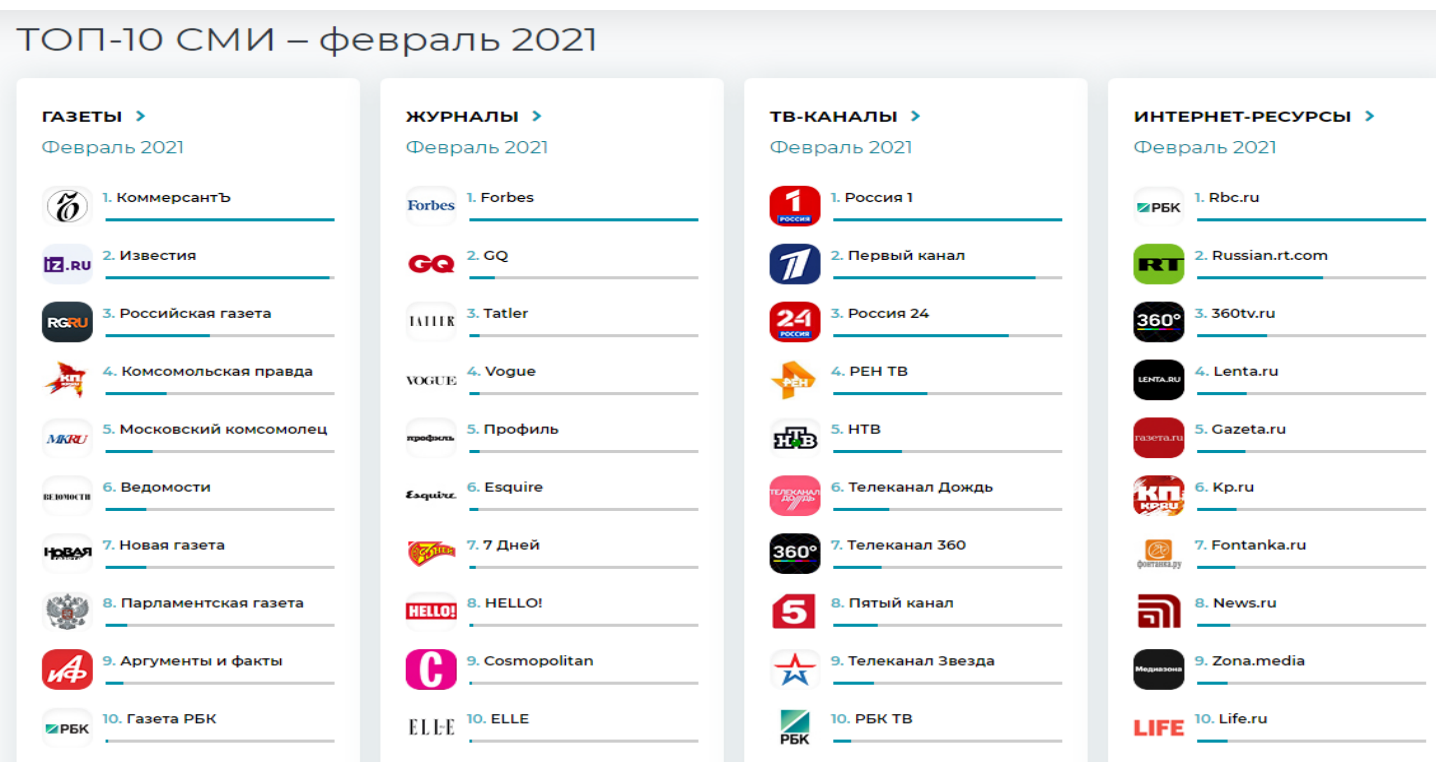

Puc. 1. Топ-10 СМИ, февраль 2021 г.

Fig. 1. Top-10 of Mass media, February 2021

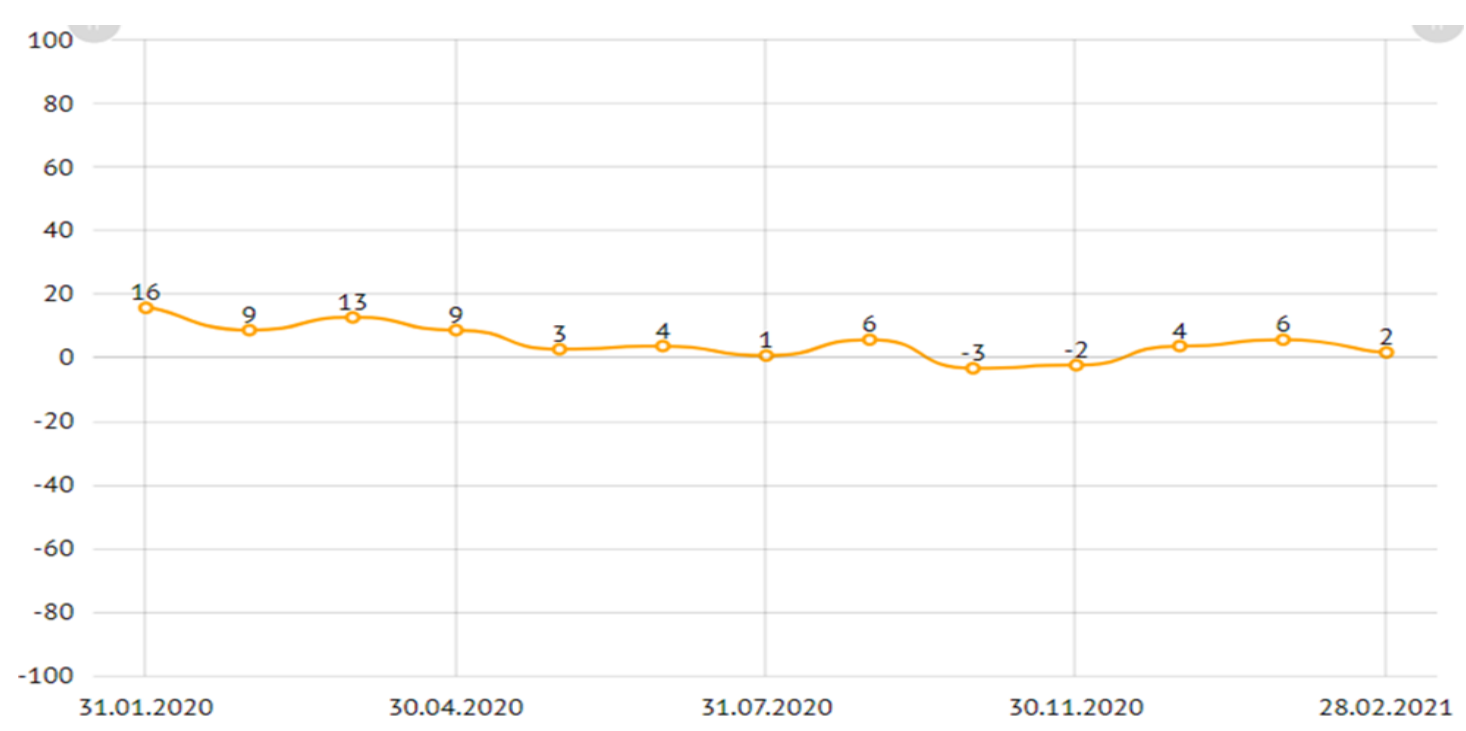

Pис. 2. Индекс одобрения деятельности средств массовой информации Fig. 2. Media Approval Index

В марте 2021 г. ВЦИОМ провел еще одно исследование о пользовании Интернетом и телевидением среди россиян [18]. $53 \%$ респондентов активно используют телевидение и Интернет (не реже нескольких раз в неделю). Наиболее активно это делают россияне в возрасте 35-59 лет (61-64\%). Это аудитория снизилась на 9 пунктов с 2018 г. При этом растет численность людей, кто отказался от телесмотрения в пользу Интернета, их доля увеличилась на 15 пунктов с 2018 г. и составила $28 \%$. При сокращении на 5 пунктов с 2018 г. доля людей, не пользующих Интернетом, значительна $17 \%$, особенно в возрастной группе старше 60 лет - $45 \%$.

Первой подзадачей данной части исследования было выявление основных источников информирования граждан Российской Федерации о последних событиях в стране. В результате было обнаружено, что в настоящий момент о событиях в стране граждане предпочитают узнавать прежде всего посредством просмотра федеральных теле- 
визионных каналов и программ, а также путём знакомства с материалами разнообразных интернет-ресурсов.

Далее стояла подзадача - выявить наиболее востребованные у населения средства массовой информации. Телевидение на данный момент продолжает оставаться важнейшим каналом информирования населения о федеральных новостях. При этом безусловными лидерами рейтинга зрительских предпочтений являются телеканалы «Россия 1», «Первый канал», «Россия 24», занимающие 1-е, 2-е и 3-е места соответственно. Весомым и значимым для россиян является такой способ повышения осведомлённости о последних новостях, как знакомство с материалами интернет-СМИ. Согласно полученным в ходе исследования данным, первые три позиции занимают «РБК», «RT на русском» и «Телеканал 360».

Третьей подзадачей было определение уровня одобрения деятельности средств массовой информации гражданами Российской Федерации. Исследования показали, что большинство пользователей средств массовой информации оценивает транслируемые ими материалы как объективные, отражающие реальное положение дел и потому вызывающие доверие. Деятельность СМИ одобрили свыше 42 \% опрошенных, порядка 40 \% не одобрили. При этом в динамике индекс одобрения значительно снизился с 31 января 2020 г.

При анализе регионального и муниципального сегмента СМИ и новых медиа были выявлены некоторые особенности. Во-первых, при анализе уровня доверия жителей Архангельской области к средствам массовой информации и новым медиа [19] были результаты, представленные в табл. 1.

Таблица 1. Уровень доверия населения различным социальным институтам, \% Table 1. Level of public confidence in various social institutions, \%

\begin{tabular}{|l|c|c|c|c|c|}
\hline $\begin{array}{c}\text { Социальный институт } \\
\text { Social Institute }\end{array}$ & $\begin{array}{c}\text { Полностью за- } \\
\text { служивают } \\
\text { Сompletely } \\
\text { trustworthy }\end{array}$ & $\begin{array}{c}\text { Не совсем } \\
\text { заслуживают } \\
\text { доверия } \\
\text { Not entirely } \\
\text { trustworthy }\end{array}$ & $\begin{array}{c}\text { Полностью не } \\
\text { заслуживают } \\
\text { Сompletely } \\
\text { untrustworthy }\end{array}$ & $\begin{array}{c}\text { Затрудняюсь } \\
\text { ответить } \\
\text { I find it diffi- } \\
\text { cult to answer }\end{array}$ & $\begin{array}{c}\text { Индекс } \\
\text { Index }\end{array}$ \\
\hline Интернет/Internet & 13,20 & 55,70 & 21,00 & 10,00 & $-7,80$ \\
\hline $\begin{array}{l}\text { Социальные сети } \\
\text { Social network }\end{array}$ & 13,00 & 51,40 & 26,00 & 9,60 & $-13,00$ \\
\hline Телевидение/Television & 13,40 & 38,60 & 43,90 & 4,20 & $-30,50$ \\
\hline
\end{tabular}

Рассматриваемые нами социальные институты вошли в группу с отрицательным индексом доверия. Максимум недоверия принадлежит телевидению (44 \% недоверяющих, практически каждый второй), далее следуют социальные сети (26 \%) и Интернет (21\%).

Затем авторами статьи был рассмотрен индекс доверия населения СМИ и новым медиа в зависимости от уровня дохода (табл. 2) [19].

Средства массовой информации, телевидение, Интернет, социальные сети остаются аутсайдерами доверия, в том числе среди малоимущих граждан. Именно на это необходимо обратить внимание лицам, принимающим решения. СМИ - это не только способ обратной связи между государством и индивидом, но и механизм информационного обеспечения общественных процессов. СМИ и новые медиа влияют на формирование единства общества, а также способны внедрять в сознание человека различные социальные практики и модели поведения. При возникновении недоверия этот инструмент перестает быть эффективным [19].

\footnotetext{
${ }^{1}$ Индекс - разница между положительными и отрицательными ответами, указывает на превалирование положительных или отрицательных ответов (без учета нейтральных оценок).
} 
Таблища 2. Индекс доверия населения СМИ и новым медиа с распределением по доходу, \%

Table 2. Index of public confidence in mass media and new media with distribution by income, $\%$

\begin{tabular}{|l|c|c|c|c|}
\hline \multirow{2}{*}{$\begin{array}{c}\text { Социальный институт } \\
\text { Social Institute }\end{array}$} & \multirow{2}{*}{$\begin{array}{c}\text { Область } \\
\text { Region }\end{array}$} & $\begin{array}{c}\text { Распределение по уровню дохода /Distribution by income } \\
\text { below average }\end{array}$ & средний/average & $\begin{array}{c}\text { выше среднего } \\
\text { above average }\end{array}$ \\
\hline Интернет/Internet & $-7,80$ & $-8,00$ & $-5,60$ & $-12,10$ \\
\hline Социальные сети/Social network & $-13,00$ & $-9,60$ & $-13,70$ & $-15,80$ \\
\hline Телевидение/Television & $-30,50$ & $-29,80$ & $-34,90$ & $-28,90$ \\
\hline
\end{tabular}

Во-вторых, были выявлены недостатки в характере подачи информации в региональных средствах массовой информации. Данные опроса населения Архангельской области показали, что на первом месте для жителей стоит потребность получения качественных аналитических материалов и объективной информации (27 \% респондентов), вторую и третью позицию с результатом $26 \%$ занимают необходимость ярких историй простых людей и возможность быть услышанными, донести свою позицию, осветить проблемы. Другими словами, в СМИ люди видят «голос справедливости и правды». В большей степени респонденты указывали на варианты, характеризующие не развлекательную, а информационно-образовательную функции СМИ [19].

Следовательно, должна вестись работа по реализации названных пожеланий, в результате чего информационный контент должен представлять собой комплекс качественной, объективной информации, отражающей разные мнения и показывающий реальные истории успеха простых жителей региона.

Очевидно, что для сохранения и повышения привлекательности существующих средств массовой информации для жителей Архангельской области, а особенно населения больших городов, молодёжи, людей с высоким уровнем образования и других «прогрессивных» групп, для которых традиционные формы СМИ теряют свою значимость и актуальность, форма подачи информационных сведений должна совершенствоваться, видоизменяться, соответствовать современным тенденциям.

Еще одна задача - это выяснить, что человек предпринимает при попадании в трудную жизненную ситуацию и какие действия он осуществляет для непопадания за черту бедности. Для этого в рамках исследования респондентам был задан вопрос: «Представьте, что Вы оказались в трудной жизненной ситуации (потеря работы, нехватка финансов, невозможность работать из-за болезни или ухода за родственником) и зашли в Интернет, чтобы найти информацию о том, что бы могло Вам помочь. Что бы Вы написали в поисковой строке?». В опросе приняло участие 123 респондента из Архангельской области, и наиболее популярными ответами оказались варианты, представленные в табл. 3 .

Полученные данные показывают нам, что большинство респондентов ориентированы на изменение ситуации с помощью активных действий по поиску работы. Это позитивный момент. Также хотелось бы отметить, что 7,32 \% опрошенных сформулировали свой запрос как «Социальная помощь, соцзащита, пособия и пр.». При этом аудитория запроса по социальной помощи явно имеет потенциал к активному росту. Таким образом, имеет место слабая информированность целевой аудитории вообще о существовании механизмов государственной поддержки и помощи. Второй по популярности ответ варианты выражения негативных эмоций респондентов, незнания и нежелания менять ситуацию - это также потенциальная аудитория при качественном информировании как для раздела «Поиск работы», так и для раздела «Социальная помощь, соцзащита, посо- 
бия и пр.». Перевод этой части аудитории в соответствующие разделы возможен при помощи качественного информирования, например через формирование историй успеха конкретного человека в преодолении трудной жизненной ситуации, а также визуализацию сценариев и алгоритмов действий в случае попадания в ловушку бедности.

таблица 3. Результаты опроса (август 2021 г.)

Table 3. Survey results (August 2021)

\begin{tabular}{|l|c|c|}
\hline \multicolumn{1}{|c|}{$\begin{array}{c}\text { Ответ } \\
\text { Answer }\end{array}$} & $\begin{array}{c}\text { Количество, чел. } \\
\text { Number, people }\end{array}$ & $\%$ \\
\hline Поиск работы/Job search & 56 & 45,53 \\
\hline Выражение недовольства и эмоций/Expression of discontent and emotions & 31 & 25,20 \\
\hline Работа удаленно/Working remotely & 18 & 14,63 \\
\hline $\begin{array}{l}\text { Социальная помощь, соцзащита, пособия и пр. } \\
\text { Social assistance, social protection, benefits, etc. }\end{array}$ & 9 & 7,32 \\
\hline $\begin{array}{l}\text { Kак сэкономить средства (например, на приготовлении пищи) } \\
\text { Ноw to save money (for ехаmple, on cooking) }\end{array}$ & 7 & 5,69 \\
\hline Кредит/Credit & 2 & 1,63 \\
\hline Итого/Total & 123 & 100 \\
\hline
\end{tabular}

Для контрольного анализа авторы использовали систему www.wordstat.yandex.ru, которая позволяет сформировать статистику запросов на Яндексе, включающих заданное слово или словосочетание, и похожих запросов ${ }^{2}$. Проанализируем наиболее популярный запрос «Поиск работы» и наиболее рисковый запрос для целевой аудитории «Микрозаймы, кредит». По запросу «Поиск работы» за последний месяц (запрос проведен 27 июля 2021 г.) в системе «Яндекс» осуществлено чуть менее 220000 показов. При этом абсолютное большинство показов (147 240 единиц, или 66,94 \%) осуществляется посредством мобильных устройств. Этот факт необходимо также учитывать при формировании информационной политики. При анализе запросов, похожих на «Поиск работы», обращает на себя внимание смежный запрос «Сайт работа» (656 683 показа в месяц). В связи с этим рекомендуем органам государственной власти использовать активнее популярные ресурсы по этой категории. Стоит отметить, что второй по популярности подзапрос в разделе «Сайт работа» - это запрос «Сайт работа + в России» (199 764 показа), который при использовании в поисковой системе «Яндекс» ведет непосредственно на официальный сайт общероссийской базы вакансий «Работа в России» (www.trudvsem.ru). В отношении анализа по Архангельской области - за месяц показатели более чем скромные: всего 710 показов ${ }^{3}$, при этом 406 показов сделаны по г. Архангельску. Региональная популярность ${ }^{4}$ находится на пониженном уровне и составляет $83 \%$, что также требует внимания и доработки.

\footnotetext{
${ }^{2}$ Цифры рядом с каждым запросом в результатах подбора слов дают предварительный прогноз числа показов в месяц, которое вы получите, выбрав этот запрос в качестве ключевого слова. Так, цифра рядом со словом «телефон» обозначает число показов по всем запросам со словом «телефон»: «купить телефон», «сотовый телефон», «купить сотовый телефон», «купить новый сотовый телефон в крапинку» и т. п.

3 «Показов в месяц» - это абсолютное значение количества показов страниц по запросам из данного региона.

4 «Региональная популярность» - это доля, которую занимает регион в показах по данному слову, деленная на долю всех показов результатов поиска, пришедшихся на этот регион. Популярность слова/словосочетания, равная $100 \%$, означает, что данное слово в данном регионе ничем не выделено. Если популярность более $100 \%$ указывает на то, что в данном регионе существует повышенный интерес к этому слову, если меньше 100 \% - пониженный. Для любителей статистики можем заметить, что региональная популярность - это affinity index.
} 
Теперь обратимся к рискованному запросу для целевой аудитории «Микрозаймы, кредит». При не самой высокой популярности этого запроса, по результатам опроса, при проведении анализа с использованием системы www.wordstat.yandex.ru становится очевидно, что использование выражений со словом «микрозайм» (843010 показов) выше применения ранее рассматриваемого запроса «Поиск работы» (219 958 показов), что только максимизирует озвученные риски. Таким образом, даже профильные государственные организации (например, www.trudvsem.ru) имеют существенные риски быть отсеченными, и информация не попадает к целевой аудитории. Следовательно, человек, попавший в трудную жизненную ситуацию, должен быть заранее подготовлен (снабжен алгоритмами и возможными сценариями) для того, чтобы получить адресную (чаще всего безвозмездную) поддержку и помощь со стороны государства. Для этого необходимо вести постоянную системную работу, используя правильный набор слов и выражений. Существует риск популяризации запроса «Микрозаймы, кредит». Повышение закредитованности населения под высокие проценты может спровоцировать рецидивную бедность и нарастить долю бедного населения региона.

Дополнительно рассмотрев запрос «Социальная помощь, соцзащита, пособия и пр.», мы видим, что с учетом запросов, похожих на него, и в совокупности с запросом «Поиск работы» они вполне способны составить конкуренцию микрофинансированию.

В целом анализ ситуации в системе «Яндекс» говорит о необходимости и потенциале дополнительного, более таргетированного информационного стимулирования целевой аудитории.

\section{Семантический анализ использования слов, лексем и выражений}

Для создания эффективного контента (как форм, так и содержания) авторами исследования был осуществлен ряд процедур, а именно проведен подбор ассоциаций и синонимов к слову «бедность», а также анализ существующего окружения и окраски данного слова, лексем и выражений с его использованием. Далее был осуществлен этап семантического и контент-анализа.

Для поиска соответствующих ассоциаций мы использовали «Русский ассоциативный словарь» (www.tesaurus.ru). Авторы осуществили прямой поиск по запросу «бедность», без разбивки по полу с сортировкой по частоте. Всего получено реакций на стимул 102 единицы, различных реакций на стимул - 45 [20]. 9 из 45 реакций являются либо нейтральными, либо положительными. В части из них прослеживается характер противопоставления («бедность» - «богатство»), часть не имеет отношения к материальному положению индивида («души», «Достоевский»). Самая популярная ассоциация - «не порок» (частота - 35), говорит нам о том, что состояние бедности не осуждается обществом. Более того, общество его даже частично оправдывает и готово оказать помощь (позиция богатых) или не бороться (позиция бедных). Именно на этом необходимо строить дальнейшую тактику информирования.

Однако при проведении собственного опроса среди жителей Архангельской области мы получили практически стопроцентный негативный набор ассоциаций, среди которых наиболее часто встречающиеся - это «нищета», «болезнь», «безработица», «необразованность», «отсутствие жилья», «голод», «стыд», «страх». Данный набор ассоциаций позволяет увидеть не только отношение респондентов к феномену бедности (стыдно, страшно), но и основные депривации (образование, здоровье, работа, жилье), которые заботят людей.

Проведенный поиск синонимов с использованием соответствующего электронного словаря (www.sinonim.org) выявил 40 основных и 48 дополнительных синонимов [21]. 
10 наиболее часто употребляемых выглядят следующим образом: «недостаток», «нужда», «лишения», «шаром покати», «бедствие», «нищета», «ни кола ни двора», «нехватка», «крайность», «недостаточность». Все без исключения слова и выражения несут в себе негативный, ограничительный, а зачастую и уничижительный характер. Возникает явное ощущение безысходности и невозможности преодолеть ситуацию. Этот фактор также необходимо учесть при формировании информационной политики.

Далее был проведен анализ окружения и окраски слов, лексем и выражений. Проведение лексико-грамматического анализа контекстных связей слова «бедность» осуществлялось с использованием информационно-справочной системы «Национальный корпус русского языка» (www.ruscorpora.ru) [22]. В результате поиска в основном корпусе указанной системы было автоматически проанализировано 124566 документов и 321783495 слов. Количество вхождений по слову «бедность» составило 3245 раз в 1888 документах. Для детального анализа взято 363 упоминания с 2003 по 2018 г. ${ }^{5}$ При анализе синтагматики слов и их контекстных связей (с чем слово сочетается, какое действие происходит, кто является субъектом этого действия) было выявлено, что в $72 \%$ упоминаний контекстные связи носили отрицательный характер, в 16 \% упоминаний нейтральный и лишь в 12 \% упоминаниях - положительный. Наблюдается явное преобладание негативного контекста. Результаты поиска в региональном корпусе не выдали материалов, опубликованных в Архангельской области.

Таким образом, проведя анализ синонимов, ассоциаций и анализ окружения и окраски слова «бедность», мы пришли к выводу, что при использовании данного слова, а также соответствующих ему лексем и выражений обычно возникают негативные эмоции, не мотивирующие индивида к активным действиям по преодолению сложной жизненной ситуации.

При формировании содержания любого сообщения необходимо последовательно учитывать и анализировать три момента. Во-первых, как информация репрезентируется в СМИ и новых медиа сейчас? Во-вторых, какой эмоциональный и информационный фон сформирован в голове конкретного потребителя контента? И, в-третьих, какая репрезентация нужна в последующем для получения оптимального результата?

В результате нашего исследования было выявлено, что достаточно часто используются такие выражения, как «за чертой бедности» и «борьба с бедностью». Бедность представляется некой формой, которая имеет свои границы, которые необходимо перейти. Сделать это должен сам индивид, приложив определенные усилия. Чаще всего он этого делать либо не желает (отсутствие мотивации), либо стесняется позиционировать себя в качестве малоимущего (психологический посыл - «бедным быть стыдно»). Вместе с тем борьба с бедностью в основном позиционируется создателями контента как государственная задача, следовательно, решить ее должно государство. Вот именно на этом этапе и проявляется явное противоречие. У конкретного человека возникает состояние когнитивного диссонанса: с одной стороны, перейти черту бедности - это индивидуальная трудная, зачастую постыдная задача, и решать ее, исходя из представленного содержания, человек не мотивирован. С другой стороны, вся ответственность контекстно возложена на государство, которое на самом деле должно формировать стимулы, направленные на соответствующие индивидуальные мотивы человека.

Дополнительно авторами отмечается появление другой крайности, попытки облагораживания бедности через ее эстетизацию и геймизацию (представление в виде игры, некого соревнования). Ряд изданий [23] пытается позиционировать бедность как игру, в которой можно принять участие по своей воле, в любой момент вернувшись к привыч-

\footnotetext{
${ }^{5}$ Данных позднее 2018 г. система не содержит.
} 
ной комфортной жизни. Данный дискурс, по мнению авторов, не только не помогает решить проблему, но и может вызвать дополнительные негативные, возможно, агрессивные реакции со стороны целевой аудитории. Ключевым же направлением развития данной тематики эксперты видят в уточнении и усложнении контекста бедности в российских медиа. Еще одним актуальным направлением может послужить представление данного феномена более искренне и реалистично. По мнению нидерландской исследовательницы Эллен Руттен, которая определяет это как запрос на аутентичное несовершенство [24], данное направление (новая искренность) характерно для посткоммунистических обществ [25].

Выход авторам видится в реализации следующей модели. На первом этапе происходит формирование нового перечня слов и выражений, «попадающих» в мотивы представителей целевой аудитории. На втором этапе формируются новые сценарии, позиционирующие индивида как человека, способного решать свои проблемы, а государство - как необходимого и эффективного помощника, готового предоставить эффективный инструментарий.

Тем самым мы меняем отношение человека и к самому феномену бедности (это не стыдно, это не порок, это временные трудности, которые возможно преодолеть), и к алгоритмам повышения своего благосостояния (если я захочу, то государство мне поможет). Методика трансформации негативного восприятия должна быть направлена на позитивный или нейтральный смысл. Нужно «переписать» сценарий в голове у человека, в частности уйти от слов «должен», «обязан», «преодолеть». Необходимо применение глаголов и существительных без негативного восприятия. Скорее всего, потребуется осуществить переход от вопроса «Как побороть бедность?» к вопросу «Как справиться с трудной жизненной ситуацией?» или «Как повысить уровень своего благосостояния?». Также необходим переход в сценариях от концепта «бедный» к концепту «попавший в трудную жизненную ситуацию», а от «борьбы с бедностью» к «повышению благосостояния».

Анализ поисковых запросов в системе «Яндекс» показал (табл. 4), что интерес к вариантам «меры социальной поддержки» и «трудная жизненная ситуация» в десятки раз превышает интерес к запросам «борьба с бедностью» и «преодоление трудной жизненной ситуации». Это еще раз подтверждает сформулированный ранее вывод о нежелании индивида что-либо преодолевать.

Таблища 4. Анализ поисковых запросов в системе «Яндекс» (на 28 июля 2021 г.) Table 4. Analysis of Yandex search queries (as of July 28, 2021)

\begin{tabular}{|l|c|c|}
\hline \multicolumn{1}{|c|}{$\begin{array}{l}\text { Поисковый запрос } \\
\text { Search query }\end{array}$} & $\begin{array}{c}\text { Количество результатов } \\
\text { Number of results }\end{array}$ & $\begin{array}{c}\text { Количество показов в месяц } \\
\text { Number of views per month }\end{array}$ \\
\hline Борьба с бедностью/Fighting poverty & 8000 & 1521 \\
\hline $\begin{array}{l}\text { Меры социальной поддержки } \\
\text { Social support measures }\end{array}$ & 9000000 & 53000 \\
\hline $\begin{array}{l}\text { Трудная жизненная ситуация } \\
\text { Difficult life situation }\end{array}$ & 8000 & 33000 \\
\hline $\begin{array}{l}\text { Преодоление трудной жизненной ситуации } \\
\text { Overсоming a difficult life situation }\end{array}$ & 5000000 & 823 \\
\hline
\end{tabular}

А как же региональные и муниципальные СМИ и новые медиа реагируют на эти вызовы? Для того чтобы узнать это, нами был проведен семантический анализ материалов в СМИ и новых медиа Архангельской области. В связи с тем, что негативный контекст и восприятие слова «бедность» были нами ранее обоснованы, а следовательно, анализировать его не имело никакого смысла, задача была несколько откорректиро- 
вана и сформулирована следующим образом: «как часто в одном информационном материале в региональных и муниципальных СМИ и новых медиа встречаются фразы «трудная жизненная ситуация» и «меры социальной поддержки», каково окружение данных фраз и контекст использования?». С помощью информационно-аналитической системы «Медиалогия» был осуществлён поиск материалов, в которых содержались указанные выражения. Были проанализированы материалы, выпускаемые 1 января 2017 г. по 29 июля 2021 г. в 93 самых популярных региональных и муниципальных средствах массовой информации и 100 муниципальных пабликах в социальной сети «ВКонтакте». В результате был получен массив из 101 информационного материала, в том числе 86 оригинальных (без перепечаток). Далее из полученного массива ручным методом были отобраны материалы, которые по контенту можно отнести к рассматриваемой тематике. В итоге качественный анализ был проведён на основе массива, состоящего из 49 публикаций. В результате проведенного анализа были сделаны следующие выводы:

1. Наблюдается явный дефицит количества материалов по заявленной тематике, их несистемная и нерегулярная публикация. С 2019 г. присутствует тенденция к снижению количества размещаемых материалов. При этом идет серьезный перекос в сторону информации о социальной поддержке при организации детского отдыха (17 публикаций из 101). Также присутствует дублирование федеральной повестки.

2. Вторым существенным перекосом является размещение значительного массива информации о действиях государственных чиновников, депутатов различного уровня, а также публикации о мероприятиях различной направленности (круглые столы, фестивали и т. п.). Материалы носят официозный характер при совершенно нейтральной окраске (выявлено 33 позиции).

3. При этом активно публикуются материалы, поясняющие те или иные меры социальной поддержки. Например, только социальному контракту посвящено 11 материалов. Таким образом, присутствует фрагментарная, несистемная презентация алгоритмов действий в трудной жизненной ситуации.

4. Фактически отсутствует сценарная составляющая, направленная на описание историй успеха конкретных людей, преодолевших трудную жизненную ситуацию, используя государственные меры социальной поддержки.

5. При выборе информационных каналов упор делается на газеты (56 из 101 материала) и интернет-СМИ (42 из 101 материала). При этом телевидение, являясь наиболее популярным каналом потребления информации, практически не задействовано.

При анализе 100 пабликов с общей аудиторией 108000 человек в социальной сети «ВКонтакте» было выявлено всего шесть материалов (100 \% нейтральные по тональности) за последние три месяца, что также свидетельствует о необходимости усилить работу как качественно, так и количественно. В связи с незначительным массивом информации дальнейший анализ представляется нецелесообразным.

\section{Выводы}

Средства массовой информации и новые медиа, несомненно, являются важным фактором влияния на преодоление феномена бедности в Российской Федерации. На основании проведенного анализа авторы исследования пришли в ряду выводов, а именно:

1. С развитием глобальной системы массовой коммуникации (в том числе, доступности средств массовой информации и новых медиа) коммуникативная концепция структурирования социальности актуальна как никогда. При формировании современ- 
ных теоретических моделей и реализации практических механизмов влияния СМИ и новых медиа на феномен бедности целесообразно применение интегративного подхода.

2. Большая часть населения Российской Федерации рассматривает телевидение в качестве основного источника получения информации. При этом растет численность людей, кто отказался от телесмотрения в пользу Интернета. Лидером среди видов контента все также остаются фильмы и видеоролики. Но индексы одобрения и доверия к средствам массовой информации и новым медиа снижаются.

3. Основным источником получения новостных сведений о жизни региона и своего населённого пункта для населения области является региональное и местное телевидение. Помимо регионального и местного телевидения к основным источникам получения информации о региональных и местных новостях можно отнести интернетсайты и группы в социальных сетях. Особое внимание стоит уделить увеличению доли жителей, вовлеченных в группы в социальных сетях. Последние годы этот источник информации становится все более востребованным для респондентов всех возрастных групп. Каналы потребления информации, предпочитаемые малообеспеченной категорией граждан, принципиально не отличаются от общей тенденции по региону.

4. Дискурс, создаваемый институтами власти, не вызывает большого интереса у целевого сообщества. Существенная часть публикаций в региональных СМИ носит официальный, а точнее официозный характер. При проведении денотативного анализа текстов выявлено преобладание официозности макротем публикуемых материалов. За официальными высказываниями пользователю зачастую трудно выделить необходимые микроситуации, связанные с повышением благосостояния домохозяйства.

5. Сценарный анализ показал, что крайне редко в контенте используются эффективные схемы, которые в дальнейшем формируют модели поведения индивида. Человек на основе сценария выбирает объект и субъект действий, и именно правильно построенный образец способен воздействовать на внутренние мотивы человека и стимулировать положительное действие. Вот почему важно при формулировании контента правильно в позитивном или нейтральном ключе описывать и индивида, и ситуацию, в которую он попал, а также серьезно относиться к созданию сценария каждого информационного материала. При проведении эмотивного анализа также было выявлено, что зачастую происходит несовпадение восприятия смысла автора и адресата.

6. Проведя анализ синонимов, ассоциаций слова «бедность», мы пришли к выводу, что при использовании данного слова, а также соответствующих ему лексем и выражений обычно возникают негативные эмоции, не мотивирующие индивида к активным действиям по преодолению сложной жизненной ситуации.

7. Концептуальный способ семантического анализа также показал, что за словом «бедность» и его окружением чаще всего прослеживается отрицательное восприятие, что, в свою очередь, может спровоцировать чувство злости, бессилия и невозможности изменить ситуацию у конкретного потребителя информации.

8. Использование поисковых интернет-систем в качестве основного канала информирования очень рискованно, т. к. при употреблении популярных запросов они выдают перечень, состоящий из адресов сайтов микрокредитных организаций в большей степени и благотворительных фондов - в меньшей. Профильные органы государственной власти автоматически отсекаются, и информация не попадает к целевой аудитории. При этом полученные данные показывают нам, что большинство респондентов ориентированы на изменение ситуации с помощью активных действий по поиску работы, но имеет место слабая информированность целевой аудитории вообще о существовании механизмов государственной поддержки и помощи. Анализ ситуации в системе «Ян- 
декс» говорит о необходимости и потенциале дополнительного, более таргетированного информационного стимулирования целевой аудитории.

9. Также существует риск популяризации запроса «Микрозаймы, кредит». Повышение закредитованности населения под высокие проценты может спровоцировать рецидивную бедность и нарастить долю бедного населения региона. При этом люди готовы заниматься поиском необходимой информации об альтернативных моделях поведения, и именно здесь заложен потенциал для развития информирования органами государственной власти с использованием новых медиа. Например, формирование историй успеха конкретного человека в преодолении трудной жизненной ситуации, а также визуализация сценариев и алгоритмом действий в случае попадания в ловушку бедности. Сейчас эта аудитория микрофинансовых организаций, но она может и должна быть переориентирована в сторону мер государственной поддержки.

10. Существует потребность в изменении количества, содержания (в том числе, семантического ядра) и форм информационных материалов. Количество материалов недостаточное, размещение носит несистемный характер. Целевую аудиторию больше ориентируют на меры поддержки (безвозвратной), чем на меры развития.

\section{Заключение}

В заключении данной работы мы бы хотели представить несколько рекомендаций профильным органам государственной власти Архангельской области и муниципальным органам власти в регионе по количественной и качественной корректировке информационного пространства, которые впоследствии, на наш взгляд, могут быть использованы и в других субъектах Российской Федерации. Основной посыл рекомендаций заключается в том, что человек, попавший в трудную жизненную ситуацию, должен быть заранее подготовлен (снабжен алгоритмами и возможными сценариями) для того, чтобы получить адресную поддержку и помощь со стороны государства. Для этого необходимо вести постоянную системную работу, используя следующие аспекты:

1. Необходимо сменить основной медиа-политический дискурс, создаваемый институтами власти, для стимулирования большего интереса у целевого сообщества. Перейти от информирования о деятельности органов государственной власти к информированию об имеющихся механизмах восходящей социальной мобильности.

2. Реализовать смену основных субъектов публикаций: не «чиновник/депутат», а «человек, преодолевший трудную жизненную ситуацию». Уйти от публикаций в региональных и местных СМИ, носящих официальный, а точнее официозный характер. Изменить внутреннее содержание информационных материалов, перейти от событийной направленности к информирующей и стимулирующей.

3. Перейти от текстовых форматов (например, лонгрид) в форматы коротких тегированных видео (до 1,5 минут) и инфографик, описывающих критерии и различные алгоритмы действий при попадании (риске попадания) или нахождении в сложной финансовой ситуации.

4. Увести целевую аудиторию от стереотипного восприятия невозможности выхода из «ловушки бедности» путем формирования историй успеха (например, пользователи социального контракта). Снизить преобладание маскулинного подхода в информационном освещении.

5. Актуализировать каналы коммуникации, которые реально используются целевой аудиторией. Информационные каналы должны быть настроены и адаптированы на информирование и стимулирование основного профиля бедности в регионе. 
6. При формировании информационных материалов использовать обновленное семантическое ядро, сформировать словарь фиксированных фраз, поисковых запросов, устойчивых призывов, стимулирующих индивида к действию. Выход авторам видится в реализации следующей модели. На первом этапе происходит формирование нового перечня слов и выражений, «попадающих» в мотивы представителей целевой аудитории. На втором этапе формируются новые сценарии, позиционирующие индивида как человека, способного решать свои проблемы, а государство - как необходимого и эффективного помощника, готового предоставить эффективный инструментарий. Тем самым мы меняем отношение человека и к самому феномену бедности (это не стыдно, это не порок, это временные трудности, которые возможно преодолеть) и к алгоритмам повышения своего благосостояния (если я захочу, то государство мне поможет). Методика трансформации негативного восприятия должна быть направлена на позитивный или нейтральный смысл. Нужно «переписать» сценарий в голове у человека, в частности уйти от слов «должен», «обязан», «преодолеть». Необходимо применение глаголов и существительных без негативного восприятия. Возможно, потребуется осуществить переход от вопроса «как побороть бедность?» к вопросу «как справиться с трудной жизненной ситуацией?» или «как повысить уровень своего благосостояния?». Также необходим переход в сценариях от концепта «бедный» к концепту «попавший в трудную жизненную ситуацию», а от «борьбы с бедностью» - к «повышению благосостояния».

7. Активнее выстраивать взаимодействие профильных организаций с основными коммерческими организациями по поиску работы и выдаче микрозаймов для продвижения государственных услуг по социальному развитию и социальной поддержки. При проведении работ по продвижению электронных профильных информационных ресурсов активнее использовать запросы «поиск работы», «сайт работа» и «социальная помощь и поддержка». Предусмотреть финансирование на покупку рекламных позиций в основных поисковых системах по запросам «микрозайм, кредит». В случае невозможности финансирования использовать как в контексте, так и при тегировании материалов слова «микрозайм, кредит».

8. При заключении государственных и муниципальных контрактов со средствами массовой информации и новыми медиа ввести пункт об обязательном использовании семантического ядра и утвержденных проектов сценариев, устойчивых призывов, стимулирующих индивида к действию, а также об обязательном тегировании информационных материалов фиксированными фразами, поисковыми запросам, предоставленными профильными органами государственной власти.

9. Увеличить и систематизировать количество информационных материалов. Ориентировать целевую аудиторию прежде всего на адресные меры экономического развития и акселерации (например, социальный контракт), а не на меры категориальной финансовой поддержки.

10. Информационный план должен стать обязательной составной частью региональной программы по борьбе с бедностью и ежегодных информационных планов (как регионального, так и муниципальных).

\section{СПИСОК ЛИТЕРАТУРЫ}

1. Росстат. Статистический бюллетень «Социально-экономические индикаторы бедности». URL: https://rosstat.gov.ru/compendium/document/13293 (дата обращения 11.08.2021).

2. Ячменева М.В. Влияние социальных медиа на формирование семейных и гражданских ценностей молодежи в современной России: опыт социологического исследования // Управление устойчивым развитием. - 2019. - № 3 (22). - С. 83-88. 
3. Ушкин С.Г. Влияние виртуальных социальных сетей на протестную активность в российском обществе: автореф. дис. ... канд. социол. наук. - Саранск, 2015. - С. 25.

4. Попова Ю.А. Информационные технологии в системе формирования общественного мнения // Психология, социология и педагогика. URL: http://psychology.snauka.ru/2015/07/5560/ (дата обращения 04.08.2021).

5. Капралова С.В. Прогресс информационно-компьютерных технологий и развитие интернета как факторы формирования общественного мнения // Историческая и социально-образовательная мысль. 2013. - № 4 (20). - С. 169-172.

6. Аликперова Н.В., Виноградова К.В. Влияние социальных медиа на формирование финансово грамотного поведения молодежи // Народонаселение. - 2021. - Т. 24. - № 1. - С. 33-43. DOI 10.19181/population.2021.24.1.4.

7. Мантуров О.С. Альтернативные модели структурирования социальности // Известия Уральского государственного университета. Серия 3 «Общественные науки». - 2011. - № 2 (91). - С. 11-27.

8. Фуко М. Слова и вещи. Археология гуманитарных наук. - СПб: А-cad, 1994. - 332 с.

9. Хабермас Ю. Моральное сознание и коммуникативное действие. - СПб: Наука, 2001. - 40 с.

10. Луман Н. Общество как социальная система. - М.: Логос, 2004. - 44 с.

11. Thanos Lipowatz. Das reine Politische oder Eine (post) moderne Form der politischen Mystik // Das Undarstellbare der Politik. Zur Hegemonietheorie Ernesto Laclaus. - Wien: Turia und Kant Verlag, 1998. S. $158-176$.

12. Urs Stäheli. Zum Verhältnis von Sozialstruktur und Semantik // Soziale Systeme. - 1998. - № 4 (H2). S. 315-340. URL: http://www.soziale-systeme.ch/leseproben/staeheli.htm (дата обращения: 05.08.2021).

13. Волосников Р.А. Влияние социальных медиа на формирование и функционирование общественного мнения // Социологический альманах. - 2019. - № 10. - С. 82-90.

14. Котельникова Е.В. Влияние СМИ на формирование ценностных ориентаций современного общества // Социально-гуманитарные технологии. - 2019. - № 1 (9). - С. 22-27.

15. Аналитический отчет «Российский медиаландшафт - 2020» // AHO «Левада-Центр». URL: https://www.levada.ru/2020/05/20/rossijskij-medialandshaft-2020-2/ (дата обращения 05.08.2021).

16. Рейтинг «ТОП-10 российских СМИ - июнь 2021» // Информационно-аналитическая система «Медиалогия». URL: https://www.mlg.ru/ratings/media/ (дата обращения 05.08.2021).

17. Рейтинг «Деятельность общественных институтов». URL: https://wciom.ru/ratings/dejatelnostobshchestvennykh-institutov/ (дата обращения 05.08.2021).

18. Медиапотребление россиян: мониторинг. URL: https://wciom.ru/analytical-reviews/analiticheskiiobzor/mediapotreblenie-rossijan-monitoring/ (дата обращения 31.08.2021).

19. Ежегодный доклад Общественной палаты Архангельской области о состоянии и развитии институтов гражданского общества в Архангельской области за 2020 год. URL: https://opao.ru/docs/5779/ (дата обращения 11.08.2021).

20. Русский ассоциативный словарь. URL: http://tesaurus.ru/dict/ (дата обращения 05.08.2021).

21. Словарь синонимов русского языка. URL: https://sinonim.org/s/\%D0\%B1\%D0\%B5\%D0\%B4\% D0\%BD\%D0\%BE\%D1\%81\%D1\%82\%D1\%8C\#f (дата обращения 05.08.2021).

22. Результаты поиска в основном корпусе // Информационно-справочная система «Национальный корпус русского языка». URL: https://processing.ruscorpora.ru/search.xml?sort=i_grcreated_inv\&out= normal\&dpp=10\&spd=10\&seed $=5804 \&$ lang=ru\&req=\%D0\%B1\%D0\%B5\%D0\%B4\%D0\%BD\%D0\%BE\%D $1 \% 81 \% \mathrm{D} 1 \% 82 \% \mathrm{D} 1 \% 8 \mathrm{C} \& \mathrm{~g}=\mathrm{i} \_$doc\&format=html\&text=lexform\&mode=main\&sr=1\&nodia=1 (дата обращения 05.08.2021).

23. Ельцова К.К., Юдина Е.М. Конструирование «бедности» в российских цифровых изданиях о стиле жизни (на примере порталов «Afisha Daily» и «The Village») // Артикульт. - 2020. - № 40 (4-2020). C. $152-178$.

24. Rutten E., Kemper J., Rachmadiev F. Sublime imperfections: creative interventions in Post-1989 Europe. 2020. URL: https://Sublimeimperfections.org (дата обращения 24.08.2021).

25. Rutten E. Sincerity after communism. A cultural history. - New Haven and London: Yale University Press, 2017. - 289 p.

Поступила 05.09.2021 г. 
UDC 316.774:316.344.233

\title{
MASS MEDIA AND NEW MEDIA AS A FACTOR OF INFLUENCE ON OVERCOMING THE POVERTY PHENOMENON IN THE RUSSIAN FEDERATION
}

\author{
Ilya F. Vereshchagin 1 , \\ i.vereschagin@narfu.ru \\ Artem V. Vakhrushev ${ }^{1,2}$, \\ a.vahrushev@narfu.ru \\ ${ }^{1}$ Northern (Arctic) Federal University named after M.V. Lomonosov, \\ 17, Severnaya Dvina Embankment, Arkhangelsk, 163002, Russia \\ ${ }^{2}$ Administration of the Governor of the Arkhangelsk Region and the Government \\ of the Arkhangelsk Region, \\ 49, Troitskiy avenue, Arkhangelsk, 163000, Russia
}

Ilya F. Vereshchagin, Cand. Sc., associate professor, Northern (Arctic) Federal University named after M.V. Lomonosov.

Artem V. Vakhrushev, postgraduate student, Northern (Arctic) Federal University named after M.V. Lomonosov; counselor of the Governor of the Arkhangelsk Region.

Relevance. According to the Federal State Statistics Service of the Russian Federation 12,1\% of the population of Russia are below the absolute poverty line (they have an average per capita income below the subsistence minimum used in the country). Utilizing a relative or subjective approach in the assessment of the level of poverty will lead us to even more negative data. The purpose of this study is to define a role and influence of the mass media and new media on the formation of models for getting out of poverty traps of households that have fallen into or are in a situation of poverty. The research methods: the analysis of federal statistics, the results of surveys of the population at the regional level (in the Arkhangelsk region), semantic and content analysis of materials, analysis of synonyms and associations, as well as materials published in the media and new media using the information and analytical system «Medialogia». The findings of this study are that the mass media and new media are undoubtedly important factors of influence on overcoming the poverty phenomenon in the Russian Federation. The results of the study show that in order to provide targeted timely assistance to low-income segments of the population, in parallel with the creation of applied mechanisms of social support and economic development, it is necessary to build effective mass communication channels, the main purpose of which is to help a person who is in a difficult life situation to quickly find a source of the necessary information and use it to change his situation. At the same time, the population informing should be a priority aim. This study gives detailed recommendations to the regional and municipal authorities of the Arkhangelsk region on the quantitative and qualitative adjustment of the information space, which, in our opinion, can be used in other regions of the Russian Federation.

Key words: Poverty, the poor, mass media, new media, semantic core, search query, information and communication channels, Arkhangelsk region, internet presence, scenarios and behaviors, difficult life situation, social support measures, poverty traps, motivation, incentives.

\section{REFERENCES}

1. Rosstat. Statisticheskiy byulleten «Sotsialno-ekonomicheskie indikatory bednosti» [Statistical bulletin «Socio-economic indicators of poverty»]. Available at: https://rosstat.gov.ru/compendium/document/13293 (accessed 11 August 2021). 
2. Yachmeneva M.V. Vliyanie sotsialnykh media na formirovanie semeynykh i grazhdanskikh tsennostey molodezhi v sovremennoy Rossii: opyt sotsiologicheskogo issledovaniya [The impact of social media on the formation of family and civic values of young people in modern Russia: the experience of sociological research]. Upravlenie ustoychivym razvitiem, 2019, no. 3 (22), pp. 83-88.

3. Ushkin S.G. Vliyanie virtualnykh sotsialnykh setey na protestnuyu aktivnost $v$ rossiyskom obshchestve. Avtoreferat Dis. Kand. nauk [The impact of virtual social networks on protest activity in Russian society. Cand. Diss. Abstract]. Saransk, 2015. 25 p.

4. Popova Yu.A. Informatsionnye tekhnologii v sisteme formirovaniya obshhestvennogo mneniya [Information technology in the system of formation of public opinion]. Psikhologiya, sotsiologiya i pedagogika. Available at: http://psychology.snauka.ru/2015/07/5560/ (accessed 4 August 2021).

5. Kapralova S.V. Progress informatsionno-kompyuternykh tekhnologiy i razvitie interneta kak faktory formirovaniya obshchestvennogo mneniya [The progress of information and computer technologies and the development of the Internet as factors in the formation of public opinion]. Istoricheskaya $i$ sotsialnoobrazovatelnaya mysl, 2013, no. 4 (20), pp. 169-172.

6. Alikperova N.V., Vinogradova K.V. Vliyanie sotsialnykh media na formirovanie finansovo gramotnogo povedeniya molodezhi [The influence of social media on the formation of financially literate behavior of young people]. Narodonaselenie, 2021, vol. 24, no. 1, pp. 33-43. DOI: 10.19181/population.2021.24.1.4.

7. Manturov O.S. Alternativnye modeli strukturirovaniya sotsialnosti [Alternative models of sociality structuring]. Izvestiya Uralskogo gosudarstvennogo universiteta. Seriya 3 «Obshchestvennye nauki», 2011, no. 2 (91), pp. 11-27.

8. Fuko M. Slova i veshchi. Arkheologiya gumanitarnykh nauk [Words and things. Archaeology of the Humanities]. St. Petersburg, A-cad Publ., 1994. 332 p.

9. Khabermas $\mathrm{Yu}$. Moralnoe soznanie i kommunikativnoe deystvie [Moral consciousness and communicative action]. St. Petersburg, Nauka Publ., 2001. 40 p.

10. Luman N. Obshchestvo kak sotsialnaya sistema [Society as a social system]. Moscow, Logos Publ., 2004. $44 \mathrm{p}$.

11. Lipowatz T. Das reine Politische oder Eine postmoderne Form der politischen Mystik [The pure political or a postmodern form of political mysticism]. Das Undarstellbare der Politik. Zur Hegemonietheorie Ernesto Laclaus. Wien, Turia und Kant Verlag, 1998. pp. 158-176.

12. Stäheli U. Zum Verhältnis von Sozialstruktur und Semantik [The relationship between social structure and semantics]. Soziale Systeme, 1998, no. 4 (H2), pp. 315-340.

13. Volosnikov R.A. Vliyanie sotsialnykh media na formirovanie i funktsionirovanie obshhestvennogo mneniya [The influence of social media on the formation and functioning of public opinion]. Sotsiologicheskiy almanakh, 2019, no. 10, pp. 82-90.

14. Kotelnikova E.V. Vliyanie SMI na formirovanie tsennostnykh orientatsiy sovremennogo obshchestva [Influence of mass media on formation of modern society's value orientations]. Sotsialno-gumanitarnye tekhnologii, 2019, no. 1 (9), pp. 22-27.

15. Analiticheskiy otchet «Rossiyskiy medialandshaft-2020» [Analytical report «Russian Media Landscape2021»]. ANO «Levada-Tsentr». Available at: https://www.levada.ru/2020/05/20/rossijskij-medialandshaft2020-2/ (accessed 5 August 2021).

16. Reyting «TOP-10 rossiyskikh SMI - iyun 2021» [Rating «TOP 10 Russian media - June 2021»]. Informatsionno-analiticheskaya sistema «Medialogiya». Available at: https://www.mlg.ru/ratings/media/ (accessed 5 August 2021).

17. Reyting «Deyatelnost obshchestvennykh institutov» [Rating «Activity of public institutions»]. Available at: https://wciom.ru/ratings/dejatelnost-obshchestvennykh-institutov/ (accessed 5 August 2021).

18. Mediapotreblenie rossiyan: monitoring [Media consumption of Russians: monitoring]. Available at: https://wciom.ru/analytical-reviews/analiticheskii-obzor/mediapotreblenie-rossijan-monitoring/ (accessed 31 August 2021).

19. Ezhegodny doklad Obshhestvennoy palaty Arkhangelskoy oblasti o sostoyanii $i$ razvitii institutov grazhdanskogo obshchestva v Arkhangelskoy oblasti za $2020 \operatorname{god}$ [Annual report of the Public Chamber of the Arkhangelsk Region on the state and development of civil society institutions in the Arkhangelsk region for 2020]. Available at: https://opao.ru/docs/5779/ (accessed 31 August 2021).

20. Russkiy assotsiativny slovar [Russian associative dictionary]. Available at: http://tesaurus.ru/dict/ (accessed 5 August 2021).

21. Slovar sinonimov russkogo yazyka [Dictionary of synonyms of the Russian language]. Available at: https://sinonim.org/s/\%D0\%B1\%D0\%B5\%D0\%B4\%D0\%BD\%D0\%BE\%D1\%81\%D1\%82\%D1\%8C\#f (accessed 5 August 2021). 
22. Informatsionno-spravochnaya sistema «Natsionalny korpus russkogo yazyka» [Information and reference system «National Corpus of the Russian language»]. Available at: https://processing.ruscorpora.ru/ search.xml?sort=i_grcreated_inv\&out=normal\&dpp=10\&spd=10\&seed $=5804 \&$ lang $=$ ru $\&$ req $=\%$ D0 $\% \mathrm{~B} 1 \% \mathrm{D}$ 0\%B5\%D0\%B4\%D0\%BD\%D0\%BE\%D1\%81\%D1\%82\%D1\%8C\&g=i_doc\&format=html\&text=lexform\& mode $=$ main $\& s r=1 \&$ nodia $=1$ (accessed 5 August 2021).

23. Eltsova K.K., Yudina E.M. Konstruirovanie «bednosti» v rossiyskikh tsifrovykh izdaniyakh o stile zhizni (na primere portalov «Afisha Daily» $\mathrm{i}$ «The Village») [Discursive construction of «poverty» in Russian digital lifestyle-media (case study of the «Afisha Daily» and «The Village» publications)]. Artikult, 2020, no. 40 (4-2020), pp. 152-178.

24. Rutten E., Kemper J., Rachmadiev F. Sublime imperfections: creative interventions in Post-1989 Europe. 2020. Available at: https://Sublimeimperfections.org (accessed 24 August 2021).

25. Rutten E. Sincerity after communism. A cultural history. New Haven and London, Yale University Press, 2017. 289 p.

Received 05 September 2021. 